\title{
Common Fault Diagnosis and Troubleshooting in Automotive Air-Conditioning Refrigeration System
}

\author{
Dou Yida \\ College of Automotive Engineering, Foshan Polytechnic, Foshan, Guangdong, 528137, China \\ email: douyida@163.com
}

Keywords: Automotive Air Conditioning, Refrigeration System, Fault Diagnosis, Troubleshooting Method

\begin{abstract}
With the rapid development of social economy and the continuous improvement of per capita income, people's consumption capacity has been greatly improved, and the frequency of automobile use has also been greatly improved. At this time, the performance of automobile air conditioning directly affects the comfort of motorists and riders, and will also have a certain impact on the overall performance of automobiles. Especially in the summer hot period, the automobile air conditioning refrigeration system is in the high intensity operation state for a long time, if does not carry on the timely overhaul and the maintenance, it is easy to increase the automobile air conditioning refrigeration system breakdown probability, affects the automobile air conditioning normal use. Therefore, this paper will briefly analyze the automotive air conditioning refrigeration system, and then analyze the common faults in automotive air conditioning refrigeration system, and put forward corresponding solutions based on this, better ensure the healthy operation of automotive air conditioning, hoping to provide some valuable reference for the majority of automotive air conditioning maintenance workers.
\end{abstract}

\section{The Overall Working Principle of Automotive Air Conditioning Refrigeration System}

Automobile air-conditioned refrigeration system brings a little coolness to drivers and riders in the hot summer, gives people a better driving experience, effectively enhances people's comfort in summer driving, and can be said to be an indispensable part of the driving process of summer cars. However, the automobile air-conditioned refrigeration system needs a variety of equipment to ensure the normal operation, long-time use of automobile air-conditioning and no timely airconditioned refrigeration system maintenance work, it is easy to cause related failure problems, affecting the normal use of car owners. Therefore, it is of great significance to diagnose the common faults of automobile air-conditioned refrigeration system and put forward corresponding solutions to ensure the comfort of automobile operation.

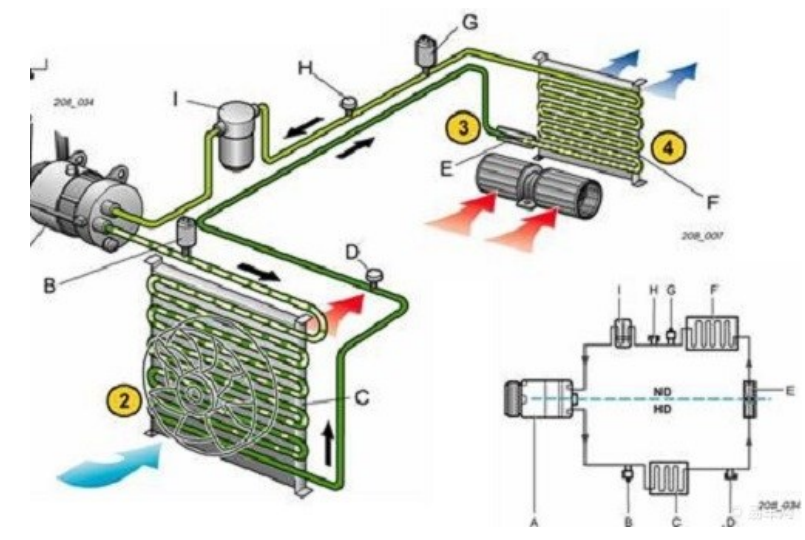

Figure 1 Automotive air-conditioned refrigeration system

The automotive air-conditioning refrigeration system consists of condensers, compressors, evaporators, expansion valves, night-vision windows, liquid-storage dryers and refrigerants (see 
figure 1). When the automotive air-conditioning refrigeration button is turned on, the equipments work simultaneously to promote the continuous circulation of refrigerants in the tube, reduce the temperature in the car compartment, and bring a more comfortable feeling to people in the driving process. In the process of automobile air conditioning and refrigeration, the gas refrigerant is compressed by compressor at high temperature, then conveyed to condenser, in this process, the temperature is reduced, the high pressure condenser is formed, the liquid storage dryer is re-entered and filtered to ensure the purity of the refrigerant, then the expansion valve is used to reduce the pressure of the high pressure refrigerant into the evaporator, and the refrigerant is converted into the gaseous state. Finally, the internal temperature of the automobile is reduced effectively by the blower. The automobile air conditioning refrigeration system is a continuous circulation process, in the automobile this airtight space through the compression, the condensation, the drying, the evaporation and the transportation and so on link realizes the high efficiency refrigeration [1].

\section{The Common Faults of Automotive Air-Conditioning and Refrigeration System and the Troubleshooting Methods}

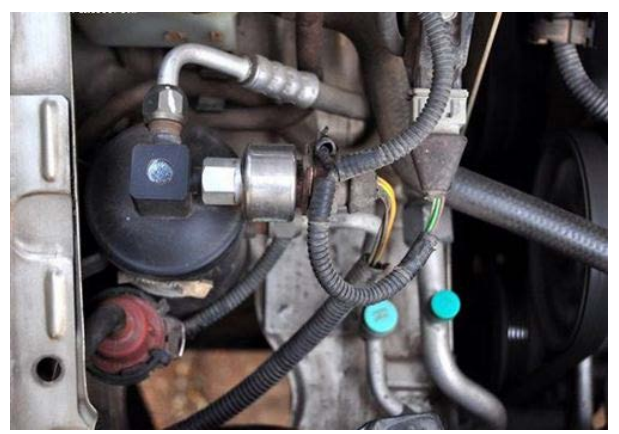

Figure 2 Automotive air conditioning refrigeration system

The automobile air-conditioned refrigeration system has brought great help to the improvement of people's travel comfort, but the refrigeration system needs multiple components to work at the same time to achieve the effective refrigeration state (figure 2). If there is a problem with some refrigeration parts, it will have a very adverse effect on the normal operation of automobile air conditioning. At present, there are three kinds of common faults in automobile air conditioning refrigeration system, one is serious, the whole automobile air conditioning refrigeration system does not work at all, and the other two kinds of problems are more common in the daily automobile air conditioning refrigeration problems, one is the poor automobile air conditioning refrigeration, the other is the large noise during the operation of automobile air conditioning refrigeration system [2]. The following we will analyze the main causes of these three cases, as well as the corresponding fault solutions.

(1) The automotive air-conditioned refrigeration system does not work at all

The automobile air-conditioned refrigeration system does not work at all, which is a serious problem in the air-conditioned system, which directly affects the normal use of the automobile airconditioned refrigeration system, and also brings great trouble to the automobile driving and riding personnel.

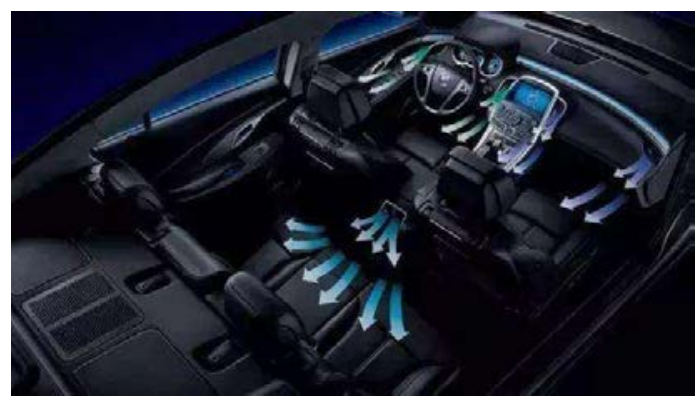

Figure 3 Automotive air-conditioned refrigeration system 
The automobile air conditioning refrigeration system needs multi-component cooperation to achieve the expected results, and the failure of the components, especially the major components, will directly lead to the failure of the automobile air conditioning refrigeration system and even produce the situation of completely not working. In the whole automobile air conditioning refrigeration system, the compressor plays a very important role, and the damage of the compressor will directly lead to the automobile air conditioning refrigeration system can not work properly. Through the analysis of the compressor, and combined with the previous maintenance experience, it is concluded that the main reason for the compressor damage is that the compressor internal cylinder, compression pad and other airtight problems, can not carry out effective compression work, or the compressor internal line short circuit and other conditions also affect the normal operation of the compressor. For the problem of compressor damage, the main solution is to first use the pressure gauge to detect the compressor inlet and outlet pressure value, to understand the change of inlet and outlet pressure, and then to improve the gear of air conditioning, in the pressure value measurement to see if the pressure value changes significantly (Fig .3). If there is no obvious change in the temperature, it is proved that the internal mechanical failure of the compressor may require a replacement of the compressor, and if the temperature is increased, but the pressure of the inlet and outlet is not changed much, it is proved that there is a problem with the sealing, so it is necessary to replace the inner rubber cushion of the compressor [3].

\section{Refrigerant Leaks or Runs out}

Automotive air-conditioned refrigeration systems are more likely to run out of refrigerants or leak out of refrigerants during long periods of service. Refrigerant is an important part of ensuring the normal operation of automotive air-conditioned refrigeration systems. [4]. If there is a certain leakage of refrigerant, it is necessary to find the leak point and repair it, whether it is refrigerant leakage or use up, it is necessary to store the refrigerant container after vacuum treatment, and then add the refrigerant again.

1) The refrigeration effect of automobile air-conditioned refrigeration system is poor

The poor cooling effect of automobile air-conditioned refrigeration system is a common problem in the process of automobile air-conditioned use. Most of them occur in automobiles with certain service life. Although it does not completely affect the normal use of automobile air-conditioned refrigeration system, if it is not dealt with in time, it will also have a more serious impact on automobile air-conditioned refrigeration system.

2) Insufficient refrigerant allowance for automotive air conditioning

Automobile air conditioning refrigerant allowance is a relatively common phenomenon. Refrigerant is a kind of consumables, especially in the summer, the automobile air conditioning is used frequently, the demand for refrigerant is bigger, if it is not added in time, it is very likely to lead to the poor refrigeration effect of the automobile air conditioning refrigeration system [5]. In view of this problem, it can be observed by liquid mirror in the process of air conditioning use, and if continuous bubbles appear, the refrigerant allowance is proved to be insufficient, and the problem can be solved by adding refrigerant.

3) Refrigerant or refrigerated oil contains more impurities

If inferior refrigerant or refrigerated oil is used in the automotive air conditioning refrigeration system, it is easy to affect the refrigeration effect of automotive air conditioning, and the inferior refrigerant and refrigerated oil contain more impurities, which will not only precipitate at the bottom of the parts, produce extremely difficult residue, but also block the pipe, directly affect the refrigeration effect, and the long-term use of inferior refrigerant and refrigerated oil will cause great harm to the whole air conditioning refrigeration system of automobile, which will be detrimental to the long-term maintenance of automobile[6]. For this problem, we should first consider the analysis of the main impurities in the inferior refrigerant and refrigerated oil. At present, the most impurities are water, which will affect the overall refrigeration effect. We can judge whether the refrigerant or freezer oil contains too much water impurity by the drying degree of the drying tank, replace the higher quality refrigerant or refrigerated oil, and replace the drying tank to effectively improve the 
cooling effect of automobile air conditioning.

Great noise is generated during the operation of the automotive air-conditioned refrigeration system

The automobile air-conditioned refrigeration system produces the bigger noise during the operation, mostly occurs in the automobile which has the longer time, and has the rougher routine maintenance work, the long time noise interference, no matter to the driver or the passenger will have the very big distress. Based on the analysis of the noise sources, the main reasons for the noise are the lack of refrigerated oil, the loose belt of the compressor or the friction between the blower, the motor fan or other parts. According to the above characteristics to do targeted inspection work, inspection of refrigerated oil allowance at the same time, air conditioning refrigeration system regular inspection and maintenance work to reduce the friction between the components.

\section{Conclusion}

To sum up, this paper mainly studies the operation of automobile air conditioning refrigeration system far away, as well as the common faults in daily life and the solution strategy to provide better service for automobile air conditioning refrigeration system. In the current society, people's demand for cars is increasing day by day, and the dependence on automobile air conditioning in the hot summer is also increasing, and the frequency of automobile air conditioning has been greatly improved. And the long time, high frequency automobile air conditioning refrigeration system operation is easy to produce the air conditioning failure problem, affects the air conditioning normal use. For this reason, we must pay attention to grasping the regularity of the failure of the air conditioning refrigeration system in the daily inspection and maintenance process of the automobile air conditioning refrigeration system, accumulate the daily maintenance experience, carry out the parts disassembly inspection work on the basis of a certain fault diagnosis, ensure the optimal maintenance, and effectively improve the maintenance efficiency and maintenance level of the automobile air conditioning refrigeration system.

\section{References}

[1] His popularity. Dihao EC718 automotive air conditioning system without refrigeration fault diagnosis and elimination. Internal Combustion Engine and Accessories, no. 13, pp. 186-187, 2019.

[2] Tian Xiaohong, Bai Yongping. A probe into the fault diagnosis and elimination method of automobile air conditioning system. Science and Technology Outlook, vol. 27, no. 4, pp. 55, 2017.

[3] Cao Kai. Diagnosis and elimination of common faults in automobile air conditioning refrigeration system. Auto and Driving Maintenance (Maintenance Edition), no. 3, pp. 86, 2018.

[4] Zhao Chunxin. Diagnosis and elimination of common faults in automobile air conditioning system without refrigeration. Modernization of Education (Electronic Edition), no. 010, pp. 182-182, 2018.

[5] Kong Xiangqiang. Analysis and diagnosis of common faults in automotive air conditioning refrigeration system. Technology and Markets, vol. 26, no. 6, pp. 167-168, 2019.

[6] Fu Jie. Structural principle and common troubleshooting method of automobile air conditioning refrigeration system. File, vol. 8, no. 33, pp. 216, 2018. 